\title{
Nawrotny częstoskurcz w łączu przedsionkowo-komorowym - odwracalna przyczyna nieadekwatnych wyładowań wszczepialnego kardiowertera-defibrylatora
}

\author{
Atrio-ventricular nodal reentry tachycardia - a reversible cause \\ of inappropriate interventions of implantable cardioverter-defibrillator
}

\author{
Beata Mańkowska-Załuska, Irmina Urbanek, Izabela Poddębska, Anna Nowek, \\ Krzysztof Kaczmarek, Jerzy Krzysztof Wranicz
}

Klinika Elektrokardiologii Katedry Kardiologii i Kardiochirurgii Uniwersytetu Medycznego w Łodzi

\section{Streszczenie}

Pacjentowi (68-letni mężczyzna) z rozpoznaną kardiomiopatią rozstrzeniową wszczepiono kardiowerter-defibrylator (ICD) w prewencji pierwotnej nagłego zgonu sercowego. W systemie home-monitoring zaobserwowano wiele arytmii, które zostały sklasyfikowane przez ICD jako epizody częstoskurczu komorowego. Arytmie były pomyślnie przerwane terapią antytachyarytmiczną, raz została zastosowana terapia wysokoenergetyczna (14 J). W zapisie z 24-godzinnego monitorowania elektrokardiograficznego metodą Holtera zarejestrowano napad arytmii z regularnymi, wąskimi zespołami QRS. Po analizie zapisów wewnątrzsercowych z pamięci ICD wysunięto podejrzenie, że był to nawrotny częstoskurcz w łączu przedsionkowo-komorowym. W czasie inwazyjnego badania elektrofizjologicznego potwierdzono diagnozę i wykonano ablację drogi wolnej łącza przedsionkowo-komorowego. Kontrola ICD przy użyciu telemonitoringu potwierdziła skuteczność zabiegu ablacji.

Słowa kluczowe: kardiowerter-defibrylator serca (ICD), nieadekwatne terapie ICD, częstoskurcz nadkomorowy, nawrotny częstoskurcz w łączu przedsionkowo-komorowym, ablacja

Folia Cardiologica 2016; 11, 2: 152-156

\section{Wstęp}

Wszczepialne kardiowertery-defibrylatory (ICD, implantable cardioverter-defibrillator) są zaopatrzone w zaawansowane algorytmy odróżniające arytmie komorowe od nadkomorowych. Mimo to $15-35 \%$ [1, 2] chorych doznaje nieadekwatnych interwencji. Najtrudniejszymi problemami do automatycznego różnicowania przez ICD są częstoskurcze z stosunkiem aktywacji komór do przedsionków 1:1. Mogą to być częstoskurcze komorowe (VT, ventricular tachycardia) z przewodzeniem wstecznym, które wymagają interwencji ICD. Częstoskurcze przedsionkowe ze sprawnym przewodzeniem zstępującym, nawrotne częstoskurcze przedsionkowo-komorowe oraz węzłowe bywają mylnie klasyfikowane jako komorowe i mogą prowokować nieprawidłowe interwencje ICD.

\section{Opis przypadku}

Sześćdziesięcioośmioletniemu mężczyźnie z kardiomiopatią rozstrzeniową w II klasie niewydolności serca według Nowojorskiego Towarzystwa Kardiologicznego (NYHA, New

Adres do korespondencji: mgr Beata Mańkowska-Załuska, Klinika Elektrokardiologii, Katedra Kardiologii i Kardiochirurgii, Uniwersytet Medyczny w Łodzi, ul. Pomorska 251, 92-213 Łódź, e-mail: b.mankowska.zaluska@gmail.com 
York Heart Association), z istotną dysfunkcją skurczową lewej komory serca (LV, left ventricle) (frakcja wyrzutowa lewej komory [LVEF, left ventricular ejection fraction $]=$ $=30 \%) \mathrm{w} 2013$ roku implantowano $\mathrm{w}$ ramach profilaktyki pierwotnej nagłego zgonu sercowego jednojamowy ICD z funkcją detekcji w kanale przedsionkowym (Biotronik Lumax 540 VR-T DX). Elektroda komorowa Linox Smart S DX, którą umieszczono w drodze odpływu prawej komory serca (RV, right ventricle), posiadała dodatkowy dipol na wysokości prawego przedsionka, wyczuwający potencjały wewnątrzprzedsionkowe. W urządzeniu ICD zaprogramowano 3 strefy detekcji arytmii komorowej: VT1 od 171/min z terapią $5 \times$ burst, $4 \times$ ramp, 7 J, 14 J, $6 \times 40$ J; VT2 od 200/min z terapią 1 burst, 14 J, 24 J, 6 × 40 J; migotanie komór (VF, ventricular fibrillation) od 240/min z terapia $40 \mathrm{~J}, 40 \mathrm{~J}, 6$ × $40 \mathrm{~J}$ [1], ze stymulacją komorową w trybie VVI z częstością 40/min. Poza rutynowymi kontrolami urządzenia w ramach Poradni Kontroli ICD chory został zaopatrzony w system domowego zdalnego monitorowania pracy układu (telemonitoring). Regularna kontrola ICD przez telemonitoring ujawniła kilkanaście napadów arytmii. Część z epizodów została zaklasyfikowana przez urządzenie jako nadkomorowa $z$ uwagi na niespełnione kryterium nagłego początku arytmii (sudden onset), a część - jako komorowa (ryc. 1). Początek każdej arytmii był poprzedzony wstawką do 4 przedwczesnych pobudzeń

\begin{tabular}{|c|c|c|c|c|c|}
\hline No. & Detection time & Type & Details & \begin{tabular}{|l|} 
Predetection \\
PP/RR \\
\end{tabular} & $\begin{array}{l}\text { Pretermination } \\
\text { PP/RR }\end{array}$ \\
\hline & 01-0ct-2014 11:14:56 & Follow-up & & & \\
\hline \multirow[t]{2}{*}{36} & 27-Sep-2014 00:40:42 & Periodic IEGM & Monitoring only & $-\cdots / \cdots$ & $-\cdots / \cdots$ \\
\hline & 15-Sep-2014 15:33:59 & Follow-up & & & \\
\hline \multirow[t]{2}{*}{35} & 28-Aug-2014 00:40:42 & Periodic IEGM & Monitoring only & $-\cdots / \cdots$ & $\cdots / \cdots$ \\
\hline & 07-Aug-2014 09:12:49 & Follow-up & & & \\
\hline \multirow[t]{2}{*}{34} & 29-Jul-2014 00:40:42 & Periodic IEGM & Monitoring only & $-\cdots / \cdots$ & $---1-\cdots$ \\
\hline & 11-Jul-2014 11:40:39 & Follow-up & & & \\
\hline 33 & 04-Jul-2014 22:41:43 & VT1 & Duration: 41s; ATP: 4 & $310 / 310$ & $574 / 575$ \\
\hline 32 & 29-Jun-2014 00:40:42 & Periodic IEGM & Monitoring only & $\ldots / \cdots$ & $-\cdots / \cdots$ \\
\hline 31 & 26-Jun-2014 20:04:06 & VT2 & $\begin{array}{l}\text { Duration: } 32 \mathrm{~s} ; \text { ATP: } 3 \text {; Shocks } \\
\text { delivered: } 1\end{array}$ & $262 / 262$ & $525 / 527$ \\
\hline 29 & 30-May-2014 00:40:42 & Periodic IEGM & Monitoring only & $\cdots / \cdots$ & $\cdots / \cdots$ \\
\hline 28 & 19-May-2014 19:28:53 & VT1 & Duration: $1 \mathrm{~min} 5 \mathrm{~s} ;$ ATP: 6 & $>1998 / 321$ & $745 / 744$ \\
\hline \multirow[t]{3}{*}{27} & 30-Apr-2014 00:40:42 & Periodic IEGM & Monitoring only & $-\cdots / \cdots$ & $--/ \cdots$ \\
\hline & 24-Apr-2014 13:12:56 & Follow-up & & & \\
\hline & 15-Apr-2014 07:35:21 & Follow-up & & & \\
\hline 26 & 12-Apr-2014 15:14:16 & VT1 & Duration: $1 \mathrm{~min} 8 \mathrm{~s} ;$ ATP: 7 & $>1998 / 314$ & $708 / 707$ \\
\hline \multirow[t]{3}{*}{24} & 31-Mar-2014 00:40:42 & Periodic IEGM & Monitoring only & $-\cdots / \cdots$ & $-\cdots / \ldots$ \\
\hline & 26-Mar-2014 11:47:42 & Follow-up & & & \\
\hline & 17-Mar-2014 13:49:13 & Follow-up & & & \\
\hline 23 & 01-Mar-2014 00:40:42 & Periodic IEGM & Monitoring only & $-\cdots / \cdots$ & $--1 / \cdots$ \\
\hline 22 & 11-Feb-2014 16:27:32 & VT1 & Duration: 19s; ATP: 2 & $>1998 / 327$ & $491 / 512$ \\
\hline 21 & $11-F e b-2014$ 08:56:32 & VT2 & $\begin{array}{l}\text { Duration: } 16 \mathrm{~s} ; \text { ATP: } 1 \text {; Shocks } \\
\text { delivered: } 1\end{array}$ & $>1998 / 282$ & $438 / 439$ \\
\hline 20 & 05-Feb-2014 03:54:58 & SVT & $\begin{array}{l}\text { Monitoring only: Duration: } \\
6 \mathrm{~min} 32 \mathrm{~s}\end{array}$ & $>1998 / 337$ & $723 / 726$ \\
\hline 19 & 02-Feb-2014 05:19:24 & VT1 & Duration: 14s; ATP: 1 & $>1998 / 314$ & $1242 / 1242$ \\
\hline \multirow[t]{2}{*}{18} & 30-Jan-2014 00:40:42 & Periodic IEGM & Monitoring only & $-\cdots / \ldots$ & $--1 / \cdots$ \\
\hline & 23-Jan-2014 14:03:43 & Follow-up & & & \\
\hline 17 & 15-Jan-2014 05:06:27 & VT1 & Duration: $1 \mathrm{~min} 50 \mathrm{~s} ;$ ATP: 7 & $>1998 / 342$ & $838 / 838$ \\
\hline 15 & 13-Jan-2014 19:04:38 & VT1 & Duration: $1 \mathrm{~min} 10 \mathrm{~s} ;$ ATP: 7 & $>1998 / 327$ & $621 / 622$ \\
\hline 13 & 08-Jan-2014 12:25:34 & VT1 & Duration: $59 \mathrm{~s} ;$ ATP: 6 & $>1998 / 318$ & $593 / 594$ \\
\hline 12 & 05-Jan-2014 00:50:15 & VT1 & Duration: $3 \mathrm{~min} 1 \mathrm{~s} ;$ ATP: 3 & $>1998 / 344$ & $781 / 782$ \\
\hline 11 & $31-$ Dec-2013 00:40:42 & Periodic IEGM & Monitoring only & $--1-$. & $\cdots / \cdots$ \\
\hline \multirow[t]{3}{*}{10} & 18-Dec-2013 10:48:13 & VT1 & Duration: $53 \mathrm{~s} ;$ ATP: 5 & $>1998 / 328$ & $787 / 789$ \\
\hline & 13-Dec-2013 13:02:45 & Follow-up & & & \\
\hline & 12-Dec-2013 20:03:09 & Follow-up & & & \\
\hline 9 & 01-Dec-2013 16:09:13 & VT1 & Duration: $1 \mathrm{~min} 19 \mathrm{~s} ;$ ATP: 7 & $>1998 / 343$ & $650 / 648$ \\
\hline 8 & 01-Dec-2013 00:40:42 & Periodic IEGM & Monitoring only & $\ldots / \ldots$ & $-\cdots / \ldots$ \\
\hline 7 & 26-Nov-2013 20:15:06 & VT2 & Duration: $1 \mathrm{~min} 23 \mathrm{~s}$; ATP: 8 & $>1998 / 298$ & $650 / 650$ \\
\hline 6 & 19-Nov-2013 03:17:41 & SVT & $\begin{array}{l}\text { Monitoring only: Duration: } \\
3 \min 48 \mathrm{~s}\end{array}$ & $>1998 / 331$ & $647 / 648$ \\
\hline 5 & 03-Nov-2013 00:02:54 & VT1 & Duration: 22s; ATP: 2 & $>1998 / 320$ & $802 / 804$ \\
\hline \multirow[t]{2}{*}{4} & 01-Nov-2013 00:40:42 & Periodic IEGM & Monitoring only & $-\cdots / 1-$. & $-\cdots / \cdots$ \\
\hline & $25-0 \mathrm{ct}-2013$ 12:59:48 & Follow-up & & & \\
\hline 3 & $23-0 c t-201323: 34: 34$ & VT1 & Duration: 33s; ATP: 3 & $>1998 / 335$ & $725 / 726$ \\
\hline \multirow[t]{2}{*}{2} & $22-0 \mathrm{ct}-201321: 31: 32$ & VT1 & Duration: 22s; ATP: 2 & $>1998 / 333$ & $727 / 726$ \\
\hline & 15-0ct-2013 11:07:16 & Follow-up & & & \\
\hline 1 & 15-0ct-2013 11:06:10 & VF & $\begin{array}{l}\text { Duration: } 15 \mathrm{~s} \text {; Shocks } \\
\text { delivered: } 1 \text {; induced }\end{array}$ & $755 / 186$ & $\cdots / \cdots$ \\
\hline
\end{tabular}

Rycina 1. Lista epizodów arytmicznych od momentu wszczepienia kardiowertera-defibrylatora (ICD, implantable cardioverter-defibrillator) do wykonania drugiego zabiegu ablacji (materiał własny) 


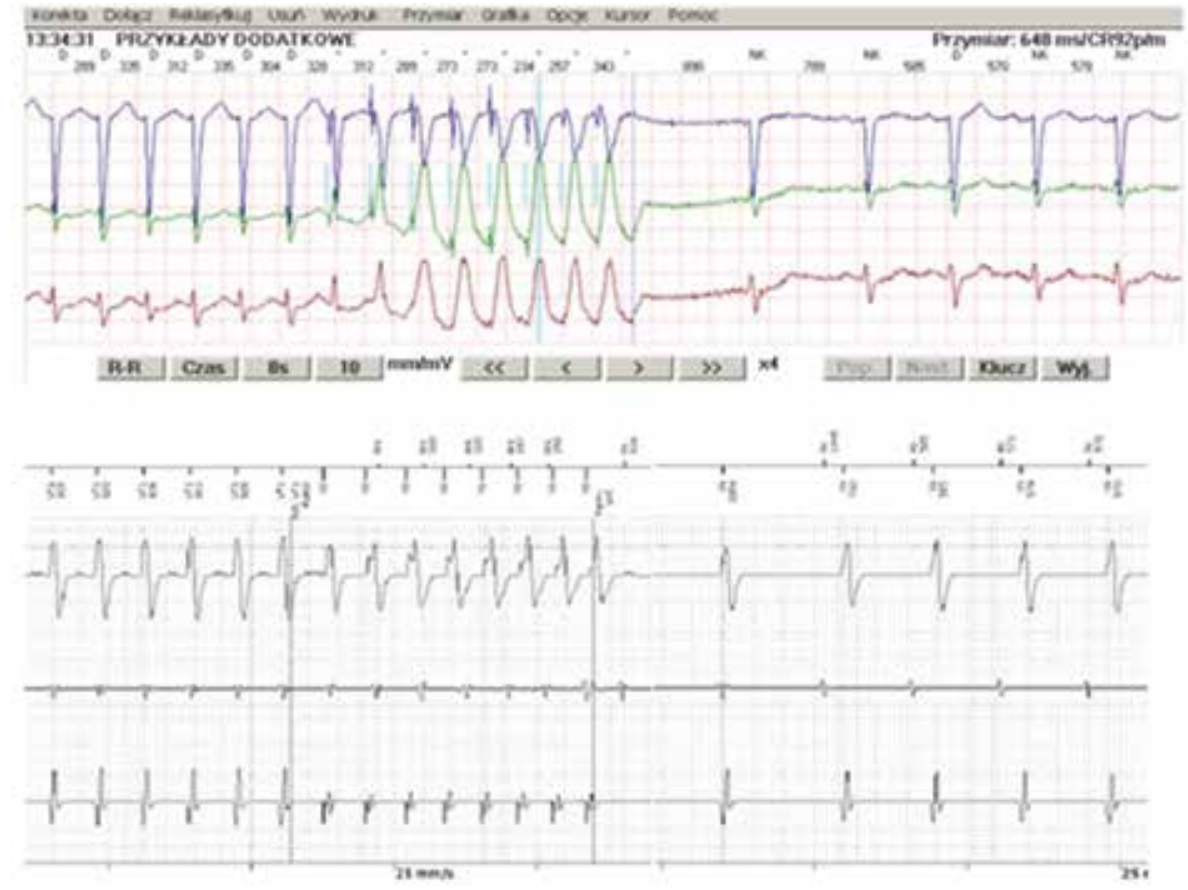

Rycina 2. Porównanie zapisu przedstawiającego początek częstoskurczu nawrotnego w węźle przedsionkowo-komorowym z pamięci wszczepialnego kardiowertera-defibrylatora (ICD, implantable cardioverter-defibrillator) i z zapisu elektrokardiograficznego metodą Holtera (materiał własny)

komorowych (PVC, premature ventricular contraction). W zapisach wewnątrzsercowych (IEGM, intracardiac electrogram) zarejestrowano częstoskurcz ze stosunkiem liczby aktywacji przedsionków i komór 1:1. Jednak mimo wyczuwania potencjałów w kanale przedsionkowym (widocznych w zarejestrowanym IEGM) urządzenie ICD nie uwzględniło ich w dyskryminacji arytmii. Wynikało to z pojawienia się potencjałów przedsionkowych w okresie zaślepienia po pobudzeniu komorowym (PVAB, post ventricular atrial blanking). Epizody arytmii były skutecznie leczone za pomoca stymulacji antytachyarytmicznych (ATP, anti-tachycardia pacing therapy) typu burst i ramp. Jedynie raz zastosowana była interwencja wysokoenergetyczna z wyładowaniem o energii $14 \mathrm{~J}$. Podczas wizyty kontrolnej pacjent zgłosił, że miał epizody kołatań serca, występujące z częstością około dwóch w miesiącu, maksymalnie raz na tydzień, o czasie trwania od kilkunastu minut do kilku godzin. Kołatania serca pierwszy raz pojawiły się u pacjenta kilka lat temu. Wątpliwości dotyczące podłoża komorowego bądź nadkomorowego arytmii wyjaśnił zapis długoterminowej rejestracji elektrokardiograficznej metodą Holtera, w którym zarejestrowano częstoskurcz nadkomorowy z wąskimi zespołami QRS (ryc. 2), przerywany za pomocą terapii ATP (ryc. 3). W połączeniu z wcześniejszą analizą IEGM wysnuto podejrzenie nawrotnego częstoskurczu nadkomorowego i skierowano pacjenta na inwazyjne badanie elektrofizjologiczne (EPS, electrophysiological study).
W trakcie EPS rejestrowano podwójne przewodzenie przez łącze przedsionkowo-komorowe przez drogę szybką (FP, fast pathway) i wolną (SP, slow pathway). Nie stwierdzono cech przewodzenia przez drogę dodatkową. Sprzęganą stymulacją programowaną z zatoki wieńcowej $\left(\mathrm{S}_{1} \mathrm{~S}_{1} \mathrm{~S}_{2}=460 \mathrm{~ms}\right.$ $260 \mathrm{~ms}$ ) wyzwolono nieutrwalony częstoskurcz nawrotny w łączu przedsionkowo-komorowym (AVNRT, atrioventricular nodal reentry tachycardia) typu slow/fast (długość cyklu arytmii $360 \mathrm{~ms}$ ) odpowiadający klinicznym arytmiom. Zmapowano okolicę trójkąta Kocha i wykonano aplikację prądu o częstotliwości fal radiowych (RF, radio-frequency) w okolicy SP, uzyskując stosowną odpowiedź (pobudzenia nawrotne, rytm węzłowy). W kontrolnym EPS w stanie podstawowym i po podaniu atropiny nie wyzwolono żadnej arytmii, obserwowano jedynie przewodzenie przez zmodyfikowaną SP. Zabieg zakończono ze względu na obserwowany w trakcie aplikacji epizod całkowitego bloku przedsionkowo-komorowego. Ponieważ kilka miesięcy po zabiegu pojawił się nawrót arytmii tożsamej z obserwowaną poprzednio, skierowano pacjenta na ponowny zabieg ablacji. Programowaną stymulacją sprzęganą z zatoki wieńcowej $\left(\mathrm{S}_{1} \mathrm{~S}_{1} \mathrm{~S}_{2}=460 \mathrm{~ms}\right.$ $270 \mathrm{~ms}$ ) wyzwolono AVNRT o długości cyklu $336 \mathrm{~ms}$. Wobec powyższego wykonano kolejną ablację prądem RF SP łącza przedsionkowo-komorowego. W kontrolnym EPS w stanie podstawowym i po podaniu atropiny żadną ze stymulacji nie wyzwolono arytmii. Od momentu wykonania ablacji nie obserwowano u chorego nawrotów arytmii. 

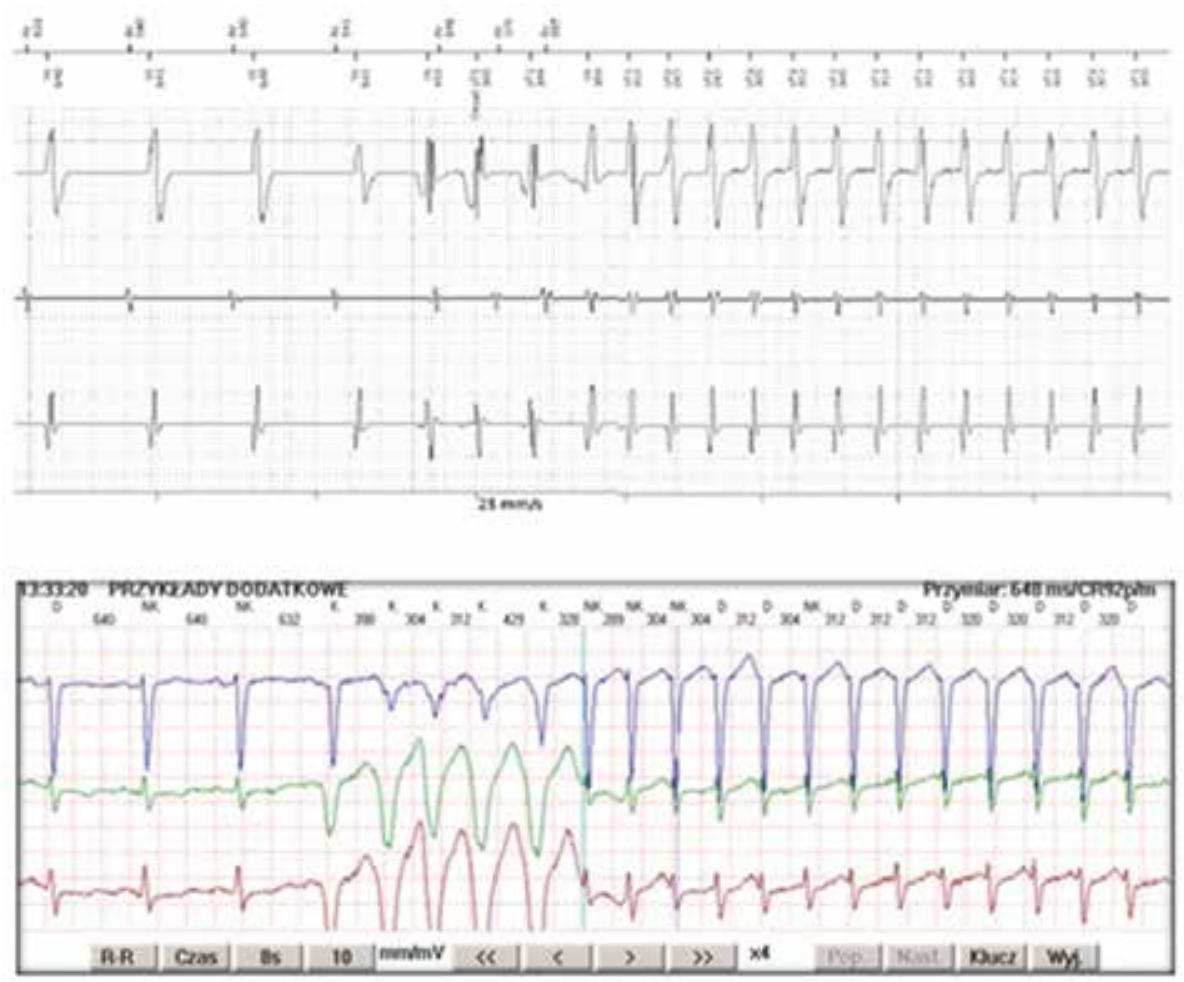

Rycina 3. Porównanie zapisu przedstawiającego zakończenie częstoskurczu nawrotnego w węźle przedsionkowo-komorowym stymulacją antytachyarytmiczną (ATP, anti-tachycardia pacing therapy) z pamięci wszczepialnego kardiowertera-defibrylatora (ICD, implantable cardioverter-defibrillator) i z zapisu elektrokardiograficznego metodą Holtera (materiał własny)

\section{Omówienie}

Częstoskurcz nadkomorowy jest przyczyną nieadekwatnych terapii u 16-22\% pacjentów z ICD [3], w tym 13,6\% wywołuje AVNRT [4]. Częstoskurcz nawrotny w łączu przedsionkowo-komorowym występuje u około 3,5\% pacjentów z ICD [2]. Mimo posiadania przez pacjenta ICD wyczuwającego sygnał przedsionkowy i komorowy oraz włączonej funkcji odróżniania arytmii nadkomorowej od komorowej (funkcja smart) urządzenie ICD kwalifikowało błędnie arytmie jako komorową. Wynika to z charakterystycznej dla AVNRT jednoczasowej aktywacji przedsionków i komór.

Arytmie, w których stosunek aktywacji komór i przedsionków wynosi 1:1, są dużym wyzwaniem dla dyskryminujących je algorytmów w układach ICD. W urządzeniach zaopatrzonych w algorytmy oparte na analizie porównawczej częstości i zmienności rytmu przedsionków i komór w czasie arytmii napadowy częstoskurcz nawrotny w łączu stanowi bardzo poważny kłopot, zwykle zakończony błędną klasyfikacją arytmii jako komorowej i wyzwoleniem terapii ICD. W tym przypadku dodatkowym czynnikiem powodującym pomyłkę diagnostyczną układu był niefortunny, choć typowy dla AVNRT, bliski czas występowania aktywacji przedsionkowej i komorowej. Ta relacja czasowa spowodowała ignorowanie aktywacji przedsionkowej, która przypadała na czas zaślepienia (odpowiadający refrakcji bezwzględnej) elektrody przedsionkowej. Część układów ICD może analizować morfologię sygnałów bliskiego i dalekiego pola rejestrowanych na elektrodzie komorowej, co poprawia skuteczność rozróżniania arytmii $[5,6]$.

Należy pamiętać, że wykrycie częstoskurczu nadkomorowego, szczególnie prowokującego interwencje ICD, powinno skłaniać do wdrożenia terapii przeciwarytmicznej. W prezentowanym przypadku był to zabieg ablacji, który wyeliminował całkowicie arytmie, bez konieczności długotrwałego dodatkowego leczenia farmakologicznego [7]. Wydaje się, że w przypadku AVNRT u chorych z ICD jest to wybór optymalny [8].

Trzeba zaznaczyć, że funkcja telemonitoringu pozwala na wczesne wykrycie zaburzeń rytmu rejestrowanych przez ICD oraz szybkie wdrożenie stosownych działań leczniczych $[9,10]$. Zapobiega to często spotykanemu pogorszeniu jakości życia pacjentów po nieadekwatnych terapiach ICD $[11,12]$.

\section{Konflikt interesów}

Autorzy deklarują brak konfliktu interesów. 


\section{Abstract}

The patient (68-year-old man) with dilated cardiomyopathy was implanted with a cardioverter-defibrillator (ICD) for primary prevention of sudden cardiac death. Home-monitoring system showed many arrhythmias which were classified by ICD as episodes of ventricular tachycardia. These arrhythmias were successfully terminated by anti-tachycardia pacing therapy and once shock was delivered (14 J). Tracings of 24-hour Holter monitoring revealed a regular narrow QRS tachycardia. After analysis of intracardiac electrogram stored in memory of the ICD suggested that the arrhythmia was an atrioventricular nodal re-entry tachycardia (AVNRT). Invasive electrophysiologic study confirmed a diagnosis of AVNRT and ablation of the slow pathway was successfully performed. ICD control using telemonitoring confirmed the effectiveness of the ablation.

Key words: ICD, inappropriate interventions of ICD, supraventricular tachycardia, atrioventricular nodal re-entrant tachycardia, ablation

Folia Cardiologica 2016; 11, 2: 152-156

\section{Piśmiennictwo}

1. Anselme F., Mletzko R., Bowes R. i wsp. Prevention of inappropriate shocks in ICD recipients: a review of 10,000 tachycardia episodes. Pacing Clin. Electrophysiol. 2007; 30 (supl. 1): S128-133.

2. Glikson M., Lipchenca I., Viskin S. i wsp. Long-term outcome of patients who received implantable cardioverter defibrillators for stable ventricular tachycardia. J. Cardiovasc. Electrophysiol. 2004; 15: 658-664.

3. Klein R.C., Raitt M.H., Wilkoff B.L. i wsp. Analysis of implantable cardioverter defibrillator therapy in the anti-arrhythmics versus implantable defibrillators (AVID) Trial. J. Cardiovasc. Electrophysiol. 2003; 14: 940-948.

4. Goldberger J.J., Passman R., Arora R., Kadish A.H. A higher than expected prevalence of AV nodal reentrant tachycardia in patients receiving implantable cardioverter-defibrillators. Pacing Clin. Electrophysiol. 2011; 34: 584-586.

5. Grönefeld G.C., Schulte B., Hohnloser S.H. i wsp. Morphology discrimination: a beat-to-beat algorithm for the discrimination of ventricular from supraventricular tachycardia by implantable cardioverter defibrillators. Pacing Clin. Electrophysiol. 2001; 24: 1519-1524.

6. Klein G.J., Gillberg J.M., Tang A. i wsp. Improving SVT discrimination in single-chamber ICDs: a new electrogram morphology-based algorithm. J. Cardiovasc. Electrophysiol. 2006; 17: 1310-1319.
7. Kadish A., Goldberger J. Ablative therapy for atrioventricular nodal reentry arrhythmias. Prog. Cardiovasc. Dis. 1995; 37: 273-293.

8. Kilborn M.J., McGuire M.A. Radiofrequency catheter ablation of atrioventricular junctional („AV nodal”) reentrant tachycardia in patients with implantable cardioverter defibrillators. Pacing Clin. Electrophysiol. 1998; 21: 2681-2684.

9. Varma N., Epstein A.E., Irimpen A. i wsp.; TRUST Investigators. Efficacy and safety of automatic remote monitoring for implantable cardioverter-defibrillator follow-up: the Lumos-T Safely Reduces Routine Office Device Follow-UP (TRUST) trial. Circulation 2010; 122: 325-332.

10. Heidbüchel H., Lioen P., Foulon S. i wsp. Potential role of remote monitoring for scheduled and unscheduled evaluations of patients with an implantable defibrillator. Europace 2008; 10: 351-357.

11. Pedersen S.S., Van Den Berg M., Erdman R.A. i wsp. Increased anxiety in partners of patients with a cardioverter-defibrillator: the role of indication for ICD therapy, shocks, and personality. Pacing Clin. Electrophysiol. 2009; 32: 184-192.

12. Sears S.F., Lewis T.S., Kuhl E.A., Conti J.B. Predictors of quality of life in patients with implantable cardioverter defibrillators. Psychosomatics 2005; 46: 451-457. 